\title{
Maternal and child health in the context of COVID-19 pandemic: evidence, recommendations and challenges
}

Pollyanna Costa Cardoso 1

https://orcid.org/0000-0002-2779-2912

Taciana Maia de Sousa 2

https://orcid.org/0000-0002-7387-154X

Daniela da Silva Rocha 3

https://orcid.org/0000-0001-6969-6841

Laura Rangel Drummond de Menezes 4

https://orcid.org/0000-0002-8422-9747
Luana Caroline dos Santos 5

iD https://orcid.org/0000-0001-9836-3704

\footnotetext{
1 Departamento de Nutrição. Universidade Federal de Juiz de Fora. Campus Governador Valadares. R. Manoel Byrro, 241. Vila Bretas. Governador Valadares, MG, Brasil. CEP: 35.010-177. E-mail: pollyanna.cardoso@ufjf.edu.br

2,4 Programa de Pós-graduação em Ciências da Saúde. Universidade Federal de Minas Gerais. Belo Horizonte, MG, Brasil.

3 Instituto Multidisciplinar em Saúde. Universidade Federal da Bahia. Campus Anísio Teixeira. Vitória da Conquista, BA, Brasil.

5 Departamento de Nutrição. Universidade Federal de Minas Gerais. Belo Horizonte, MG, Brasil.
}

\begin{abstract}
Objectives: to present the main evidence, recommendations and challenges for maternal and child health in the context of COVID-19 pandemic.

Methods: narrative review of national and international documents and reflections on the theme.

Results: the coexistence of pregnancy/puerperium and COVID-19 infection establishes many challenges. It is extremely important that the conduct should be individually adopted, covering all aspects of health in the mother-child binomial, estimating risks and benefits of each decision. Until now, it is recognized that natural childbirth should be encouraged and breastfeeding maintained, if adequate hygienic-sanitary care is ensured. Cesarean delivery and the isolation and separation of the mother-child contact without breastfeeding, will only be eligible when the clinical status of the mother or child is critical. The child must be included in all stages of health care, as this commonly asymptomatic group plays an important role in the family's transmissibility of the disease. Routine immunization should be provided, as well as clinical assistance when necessary, and families must be assisted in favor of their well-being.

Conclusion: at the moment, it is not possible to measure the consequences of this new pandemic on maternal and child health, demanding attention to its evolution and new evidences about the implications in mother and child care.
\end{abstract}

Key words SARS-CoV-2, Pregnancy, Postpartum period, Breastfeeding, Child

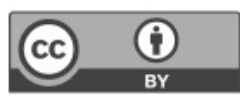




\section{Introduction}

The association between COVID-19 (coronavirus disease 2019) and SARS-CoV-2 infection (severe acute respiratory syndrome coronavirus 2) emerged in Wuhan, China, in December 2019. In late January 2020, the World Health Organization (WHO) announced that it was an international public health issue and, in March, it was classified as a pandemic. ${ }^{1}$ The clinical patterns of the disease have been described as a flu-like syndrome and severe acute respiratory syndrome. Although, most patients with COVID-19 present mild disease without complications, but some will be severe. The likelihood of negative outcomes appears to be greater among elderly, chronically ill and immunosuppressed patients. ${ }^{2}$ However, based on the conditions to be taken into consideration for a possible influenza syndrome complications, pregnant women at any gestational age, puerperium women up to two weeks after childbirth (including abortion or fetal loss) and children under 5 years old were also included in the risk groups. ${ }^{2}$

\section{Evidence}

International studies have shown that clinical symptoms of COVID-19 in pregnant women resemble to the ones observed on non-pregnant women.

In China, 118 pregnant women with COVID-19 ( $64 \%$ were infected in the third trimester) were assessed and the symptoms such as fever and cough were $75 \%$ and $73 \%$, respectively. Lymphopenia was observed in $44 \%$ of the patients and $92 \%$ presented a mild version of the disease. Severe condition was identified in $8 \%$ of the women, although there was no death in this group. ${ }^{3}$

In addition, the disease is still clinically unpredictable among pregnant women. Assumingly, COVID-19 infection can lead to unfavorable clinical evolution and obstetric outcomes in this life cycle, such as fetal distress, miscarriage, respiratory distress, prematurity and greater need of surgical childbirth. 4

Studies have reported that intrauterine SARSCoV-2 transmission from pregnant women to their babies in the third trimester does not occur. $4,5-7$ These results were confirmed by negative tests by amniotic fluid, umbilical cord blood, newborns' throat smear and breast milk samples. ${ }^{5}$ However, it is necessary to understand the effects of SARS-CoV2 infection diagnosed in the first and second trimester on maternal and conceptus health. 5 Although, some women presented comorbid condi- tions such as pre-eclampsia, gestational hypertension, gestational diabetes and uterine at ony, these were not risk factors for intrauterine SARS-CoV-2 transmission. 6

However, new evidence has emphasized the likelihood of vertical transmission. A study carried out in China, with 33 newborns of mothers with COVID-19, had positive test results for the disease in 3 neonates. Clinical symptoms observed in these newborns (with, or at risk for, COVID-19) were mild and the outcomes were favorable. The authors have suggested that, based on strict infection control and the prevention procedures implemented during childbirth, SARS-CoV-2 transmission in these cases were maternal origin. ${ }^{8}$

Another study conducted in China identified COVID-19 infection in 171 children between the ages of 1 to 15 years old. The most prevalent symptoms were coughing (48.5\%), pharyngeal erythema $(46.2 \%)$ and fever $(41.5 \%)$. Three children with coexisting disease, were required to respiratory support. Of the studied population, 149 were hospital discharged, 21 were stable in hospital wards and one patient had died. According to the authors, most of the infected children presented mild clinical conditions. 9

\section{Recommendations}

It is necessary screening for respiratory symptoms and investigate the incidence of risk factors in prenatal and maternity services in order to assure proper care for pregnant and puerperal women in the COVID-19 pandemic context.10 It is essential to provide access to specialized obstetric and fetal medicine, neonatal care, as well as mental health and psychosocial support services for women. ${ }^{11}$

If SARS-CoV-2 infection is confirmed, the Brazilian Ministry of Health (MH) ${ }^{10}$ recommends: (1) pregnant and puerperal women with flu-like symptoms should have priority care at the Family Health Units (FHU); (2) if possible, symptomatic pregnant women should have their consultations and routine exams postponed for 14 days; otherwise, they shall be assisted in an isolated environment; (3) postponed procedures should be rescheduled in a timely manner to avoid jeopardizing prenatal care follow-up.

Two obstetric outcomes should be monitored with caution: fetal growth restrictions (FGR) and prematurity. Despite the lack of current data on the evolution of pregnancy in women with SARS-CoV-2 infection, it is known that other coronavirus types (CoV-SARS and CoV-MERS) may lead to placental 
alterations and higher FGR rates. Evidence linking SARS-CoV-2 infection to teratogenesis is not representative, mainly because the reported cases, so far, referred to women infected in the second-half of their pregnancy and no newborn presented dysmorphologies. However, it is prudent to perform morphological ultrasound in pregnant women with COVID-19 in the second trimester. 10

For asymptomatic pregnant women the assistance can be maintained based on the guidelines on standard precautionary measures which already was offered for prophylaxis on H1N1 infection. ${ }^{10}$ Among these guidelines, hand hygiene, as well as avoiding agglomerations, contact with people presenting fever or respiratory infection, and touching one's mouth, nose or eyes with one's own hands are highlighted. The health team must be assertive that these guidelines are incorporated by the pregnant woman; 12 and the consultations may have longer intervals, when it is considered safe. 13

The necessity of hospitalizing pregnant women depends on the identification of the characterized severity of the infection featured by worsened general health condition, tachypnea, chest pain, low oxygen saturation and decreased consciousness level. Pregnant women with severe COVID-19 should be treated at ICUs, according to their systemic impairment degree.12 Hospitalizations deemed as necessary should be done in private rooms; patients should be accompanied by a single and asymptomatic companion with no history of contact with suspected or confirmed COVID-19 cases. This companion must constantly wear surgical mask and remain at least one meter away from the pregnant woman, whenever possible.14 Accommodation in collective pre-delivery rooms should be avoided. 15

Recommendations made by Centers for Disease Control and Prevention (CDC) ${ }^{16}$ to be followed by healthcare facilities providing obstetric care for pregnant patients comprise: 1) pregnant patients with confirmed or suspected COVID-19 should notify the obstetric unit prior to their arrival to enable the implementation of proper infection control procedures in advance; 2) visits to pregnant women with confirmed or suspected COVID-19 should be limited to individuals who are essential to patients' wellbeing and care; the person accompanying the pregnant woman should be screened for symptoms of acute respiratory disease and not allowed to enter if he/she presents fever or respiratory symptoms; 4) the use and encouragement of alternative mechanisms to enable patient-visitor interactions, such as video calling applications for additional-support indivi- duals; 5) babies born from mothers with confirmed COVID-19 infection should be considered babies with suspected COVID-19 and remain isolated from other babies.

Decisions about emergency delivery and pregnancy termination must be made in an individualized way and take into consideration different factors about the maternal and fetal clinical picture, ${ }^{2}$ such as gestational age, maternal severity condition, and fetal viability and well-being. ${ }^{11}$ In view of the need of premature pregnancy termination, the use of corticosteroids to promote fetal lung maturity should be taken into consideration, ${ }^{2}$ mainly for women at childbirth risk between the $24^{\text {th }}$ and $34^{\text {th }}$ gestational weeks. ${ }^{11}$

At this stage of the epidemic, the childbirth route should be selected based on obstetric indications and on the pregnant woman's preferences, by taking into consideration the safety of both the mother and the baby; cesarean sections should be ideally performed when there is clinical justification for such a surgical procedure.11 In analogy to women infected with CoV-SARS or CoV-MERS, women presenting good general condition, no respiratory restriction and high oxygenation rate can benefit from vaginal delivery. However, pregnancy termination through cesarean section is an alternative in severe respiratory restriction cases. 12

Umbilical cord clamping in babies born from women with influenza syndrome should be performed in a timely manner during vaginal or cesarean delivery, since it would not increase the risks of vertical disease transmission. 10

Child care should start at the maternity hospital and performed in a systematic way, as recommended by the Ministry of Health and by the Neonatology Department of the Brazilian Society of Pediatrics. ${ }^{14,17}$ Babies born from asymptomatic mothers, who did not have contact with individuals diagnosed with COVID-19 or who do not present classic symptoms, should be treated based on the recommended clinical birth-care practices. In this case, an asymptomatic companion is allowed to be in the delivery room and in the joint accommodation held in private rooms. ${ }^{17,18}$ On the other hand, additional care must be provided to babies born from mothers with suspected or confirmed COVID-19, who present stable clinical picture. Skin-to-skin contact is not advised in these cases; however, it is important to enable visual contact between mother and baby in the delivery room. The joint accommodation in private room can be maintained, although under isolation regime, by keeping the maternal bed two meters away from the crib. 14,17 If the mother's 
clinical condition is severe, the newborn must be kept in a private environment accompanied by a healthy companion. ${ }^{14,17}$ In case babies born from mothers with confirmed or suspected COVID-19 present any complications at birth, if it is of respiratory nature or not, they should be kept in intensive or intermediate care beds, without maternal visits until their $14^{\text {th }}$ day of life, which is the maximum viral transmissibility period. 14,17

Care should be taken to avoid the unnecessary stay of healthy babies in hospitals or maternity hospitals in order to limit their exposure to the virus. Thus, hospital discharge must take place in a timely manner and safeguard the continuity of care through the primary healthcare services. 15

The current recommendations made by Centers for Disease Control and Prevention 19 for breastfeeding practices to be adopted by mothers diagnosed with COVID-19 are: (1) babies kept in isolation, temporarily separated from their mothers; breastmilk must be extracted to be offered to the babies by healthy caregivers, who must follow all hygienic recommendations such as tying their hair, wearing a mask, washing their hands before and after touching the babies; (2) mother and child in joint accommodation; mothers who want to breastfeed their babies must perform all the necessary hygienic care practices before each breastfeeding.

The World Health Organization 11 and the United Nations Children's Fund 20 present consistent recommendations, which differ from those of the CDC, with respect to the benefits of breastfeeding and the insignificant transmissibility of other respiratory viruses. Thus, they advise that (1) "mothers with suspected or confirmed COVID-19 infection, who are symptomatic but in good health, and those in skin-to-skin contact", must breastfeed their children in the first hour after childbirth, or as early as possible, by respecting pre-established hygienic care procedures such as routine disinfection of surfaces the symptomatic mothers had contact with, besides the aforementioned ones; (2) "sick mothers with breastfeeding restrictions" should be encouraged to extract milk to be offered to the babies, based on safety measures focused on preventing and controlling COVID-19 infection.

The Brazilian Ministry of Health ${ }^{21}$ has adopted similar recommendations, which are also in compliance with WHO; among them are: (1) breastfeeding should be maintained in case mother and baby present stable clinical condition; (2) mothers who feel insecure about breastfeeding their child must manually extract their milk so that a healthy individual can feed the baby; (3) mothers must wear surgical mask during breastfeeding, as well as taking all personal hygiene precautions.

The literature lacks clear information on the presence of specific SARS-CoV-2 antibodies in breastmilk. However, if one takes into consideration the benefits of breastmilk for babies' immune system, growth and development, maintaining breastfeeding under pre-established hygienic care procedures is the most prudent action in promoting both maternal and child health. 22

The maintenance of breastfeeding for some children, mainly for those in neonatal intensive care, may depend on human milk donations mediated by the Brazilian Network of Human Milk Banks (rBLH - Rede Brasileira de Bancos de Leite Humano). Social isolation is expected to decrease the number of donations; however, the Brazilian Ministry of Health and the rBLH have determined specific procedures to keep human milk donation safe. Prior to the current pandemic, the flow adopted by Brazilian milk banks already had a hygienic-sanitary austerity, considered as world reference. Technical standards developed for extracting, collecting and processing human milk in Brazil would be sufficient to assure the safety of the final product. Thus, the only additional recommendation established during the COVID-19 pandemic is to contraindicate milk donation by mothers who present classic symptoms of flu-like syndrome, respiratory infection or COVID-19 diagnosis. Women who report to have had close contact with individuals suspected or confirmed COVID-19 infection should also abstain from donating breastmilk during this period.23,24

Assumingly, children can play a key role in spreading the virus, since most of them can be asymptomatic or present mild symptoms. 18 Confirmed and symptomatic cases present mean recovery time ranging from 7 to 15 days; besides, they are involved in the family contagion cycle. 25 Child care requires close contact with adult individuals, which could enable the transmission of the disease in family and community environments. This source of spread by asymptomatic patients is an important factor, since it may cause the real magnitude of SARS-CoV-2 outspread to be underestimated. 18

Therefore, children must be included in all healthcare stages - in family context, school environment and public leisure areas - based on the actions focused on promoting hand, utensil and environment hygiene, as well as social distancing. Active healthcare services should give priority to scheduled or, preferably, online care in helping to minimize physical contact, based on the recommended hygiene 
protocols. 18 Medical consultations should aim at assisting children with complications, preferably through outpatient care, to avoid unnecessary patient exposure at emergency centers. It is worth to emphasize the importance of counseling health professionals, given the high prevalence of frequent respiratory infections in the coldest months. Routine immunization (according to the vaccination schedule) should be maintained. On the other hand, patients with clinical COVID-19 signs, such as high and persistent fever and respiratory distress, should go to emergency healthcare services for proper assessment and diagnostic investigation. 18

The social distance recommended nowadays has changed families' daily lives (school activities were interrupted; parents need to work at home; and individuals' support network faces limitations) and can contribute to greater stress and anxiety for the mother and child. Thus, it is recommended to help families to adjust to their new routine. Some guidelines were developed for this situation which include: explaining children about the current situation by using age-appropriate language; establishing a routine by dividing the duties among family members; including physical and leisure activities in the family program; maintaining a healthy and balanced diet; and moderating the use of screens such as televisions, computers, tablets and cell phones. 26 The support network, although limited at this time, can also support mothers in daily tasks by helping to minimize the overload of activities.

\section{Challenges}

Pregnancy and puerperium are periods of great vulnerability for women due to hormonal adaptations, as well as to changes in their family and social context, which are associated with the child's arrival. Family support is essential in such a delicate stage. However, in times of social isolation, the necessary support for these women can be hampered by the likely distancing of family members who would assumingly be their support network. Thus, it is of paramount importance adopting procedures of individual nature capable of covering all health aspects in the mother-child binomial, and always measuring the risks and benefits of each decision to be made. ${ }^{14}$

Care provided during hospitalization for childbirth purposes is the first challenge to be faced. A study conducted in New York has shown that $87.9 \%$ of 33 pregnant women who tested positive for COVID-19 were asymptomatic. 27 Thus, the risk of contamination in pre- and postpartum housing can be high in Brazil, since the country does not test all pregnant women who arrive at the maternity hospitals. Accordingly, the ideal procedure would be to keep all pregnant women in isolation or, at least, to esta-blish the minimum distance of 2 meters between beds in joint rooms; 15 however, most maternity hospitals do not have physical capacity to do so.

It is also important to take into consideration that pregnancy alone makes women more susceptible to health issues, and that even mild COVID-19 symptoms can lead to severe obstetric outcomes. ${ }^{4}$ One of them is the need to perform surgical delivery in pregnant women presenting respiratory distress and whose baby presents compromised vital signs. Brazil presents the second highest cesarean section rate in the world - $57 \%$ of deliveries 28 - and the current pandemic may further increase this rate, considering the risks of COVID-19 for gestational outcomes. 11,12

Surgical delivery demands the participation of a larger number of health professionals and longer hospitalization, which increases the risk of exposing patients to the virus in hospital environment and reduces bed turnovers in maternity hospitals. In addition to the risks inherent to cesarean sections, selecting the anesthesia to be used is also a challenge to be faced by health professionals. A consensus of experts published in China29 recommends to take into consideration, the use of local anesthesia; however, general endotracheal anesthesia may be safer if patients present respiratory impairment during childbirth. In this case, the role played by women during childbirth, which is so important for humanized birth, gets compromised.

Given the unprecedented nature of this pandemic, planning the delivery of women with suspected or diagnosed COVID-19 is a major challenge that makes the interdisciplinary work with specialists in obstetrics, neonatology and intensive care essential.12,14 So far, the gap in studies about vaginal mucosa samples or secretions in birth channels, or in investigations about whether uterine contractions can increase the impact of the virus, limits the analysis of COVID-19 transmission during vaginal delivery and of SARS-CoV-2 impacts on the placenta. ${ }^{29}$ However, if taking into consideration that evidence points towards greater risk of virus transmission through contact between infected mothers and newborns, rather than of intrauterine transmission, 7 it is necessary to separate infected mothers from their children right after delivery. Studies still differ about the most appropriate procedure in these situations, but most of them agree that isolation is necessary when mothers or babies present unstable clinical picture. ${ }^{29}$ However, it is not yet possible to measure the damage caused by this separation after 
birth, which can last up to 14 days, due to the period of high SARS-CoV-2 transmissibility.

It is also necessary to take into consideration the potential impact on the mothers' mental health facing the pandemic at such a fragility time. Anxiety affects most pregnant women as childbirth gets closer; thus, the uncertain context associated with the progress of the COVID-19 infection can exacerbate feelings such as fear and insecurity. ${ }^{13}$ Therefore, the active listening of health professionals - even if through distance communication tools -, as well as clarifications about the procedures to be adopted at the maternity hospital and the likely childbirth outcomes can help to manage maternal emotions. Psychological support associated with emotional support given by companions is recommended, whenever possible. In addition, attention to maternal mental health should be maintained after childbirth. It is known that the first two weeks after childbirth are a period of hormonal adaptations that feature baby blues. Thus, the likely mother-baby separation can intensify these symptoms and even trigger postnatal depression. 13

Despite all the benefits from breastfeeding to the health of the mother-child binomial, insecurity about the exposure to SARS-CoV-2 has led some researchers and health professionals to discourage breastfeeding. How will it affect public health actions focused on encouraging, promoting, protecting and supporting breastfeeding? What about the prevalence of breastfeeding in Brazil, which is already so far from ideal? How will lactation and breastfeeding take place after isolation? It is known that skin-to-skin contact in the delivery room and breastfeeding babies' in their first hour of life are strong predictors to the success of this practice. Thus, it is important to focus on the guidelines for extracting breastmilk, as well as on providing adequate professional support, to enable breastfeeding to be implemented in a timely manner. Finally, what are the possible consequences for mother-child bond formation and how to establish it after isolation? Previous experiences with inevitable mother-baby separation point towards the importance of promoting bond between the newborn and another family member who fits as healthy companion, and subsequently, having professional support to help in establishing the mother-child bond. 30

In addition, maintaining the donated breastmilk supply is another matter of concern. In times of social distancing, mothers are discouraged from going to hospital environments, for individual and collective security purposes. On the other hand, collecting donated milk in households is also a challenging task, given the microbiological insecurity and the risk of infecting all individuals involved in the process. All these factors add to a more rigorous breastmilk screening process and raise great concern about the shortage of human milk in banks all over the country. If breastfeeding is not preserved, how can we assure the supply of donated human milk? How can we make human milk donation safe in quarantined and socially distanced populations? These questions raised by experts 23 demand reflections and should encourage the development of actions focused on coping with the COVID-19 pandemic.

The current moment does not yet allow measuring the consequences of this new pandemic in the maternal-child health field. The coexistence of pregnancy/puerperium and COVID-19 infection poses many challenges. This population must be monitored and, in case of confirmed cases, both the mother and the newborn must be followed up. So far, surgical delivery and isolation based on mother-child separation, without breastfeeding, should only be recommended in cases in which mothers or babies present severe clinical picture. Given this exception, natural childbirth should be encouraged and breastfeeding should be maintained, as long as hygienicsanitary care is assured. Although most pediatric cases registered, so far, had positive outcomes, the care provided to the children population should not be neglected; immunization routine should be provided, clinical assistance should be encouraged, whenever necessary, and families should get the necessary help to assure their well-being.

Finally, it is worth emphasizing that the herein described information and guidelines may change in the future, as new evidence about the implications of COVID-19 for maternal and child health is published.

\section{Authors' contribution}

Cardoso PC helped in elaborating, writing and revising the manuscript. Sousa TM, Rocha DS, and Menezes LRD helped in writing and revising the manuscript. Santos LC collaborated in the critical review of the manuscript. All authors have approved the final version of the manuscript. 


\section{References}

1. WHO (World Health Organization). Coronavirus disease (COVID-2019) situation reports, 2020. Disponível em https://www.who.int/emergencies/diseases/novel-coronavirus-2019/situation-reports

2. Brasil. Ministério da Saúde. Secretaria de Atenção Especializada à Saúde. Departamento de Atenção Hospitalar, Domiciliar e de Urgência. Protocolo de manejo clínico da Covid-19 na Atenção Especializada. 1 ed. rev. Brasília, DF; 2020. Disponível em: https://portalarquivos.saude.gov.br/images/pdf/2020/April/ 14/Protocolo-de-Manejo-Cl--nico-para-o-Covid-19.pdf

3. Chen L, Li Q, Zheng D, Jiang H, Qiao J, ZhaoY. Clinical Characteristics of Pregnant Women with Covid-19 in Wuhan, China. N Engl J Med. 2020; 382: e100.

4. Panahi L, Amiri M, Pouy S. Risks of Novel Coronavirus Disease (COVID-19) in Pregnancy: a Narrative Review. Arch Acad Emerg Med. 2020; 8 (1): e34.

5. Chen H, Guo J, Wang C, Luo F, Yu X, Zhang W, Li J, Zhao D, Xu D, Gong Q, Liao J, Yang H, hou W, Zhang Y. Clinical characteristics and intrauterine vertical transmission potential of COVID-19 infection in nine pregnant women: a retrospective review of medical records. Lancet. 2020; 395 (10226): 809-15.

6. Schwartz DA. An Analysis of 38 Pregnant Women with COVID-19, Their Newborn Infants, and Maternal-Fetal Transmission of SARS-CoV-2: Maternal Coronavirus Infections and Pregnancy Outcomes. Arch Pathol Lab Med. 2020. DOI:10.5858/arpa.2020-0901-SA

7. Dashraath P, Jing LJW, Mei XKL, Li M, Sarah L, Biswas A, Choolani M, Mattar C, Su LL. Coronavirus Disease 2019 (COVID-19) Pandemic and Pregnancy. Am J Obstet Gynecol. 2020; 222 (6): 521-31.

8. Zeng L, Xia S, Yuan W, Yan K, Xiao F, Shao J, Zhou W. Neonatal Early-Onset Infection With SARS-CoV-2 in 33 Neonates Born to Mothers with COVID-19 in Wuhan, China. JAMA Pediatr. 2020; 174 (7): 722-5.

9. Lu X, Zhang L, Li YY, Liu H, Shen K, Xu S, Wong GWK SARS-CoV-2 infection in children. N Engl J Med. 2020; 382: $1663-5$.

10. Brasil. Ministério da Saúde. Nota Técnica $n^{07 / 2020}$ COSMU/CGCIVI/DAPES/SAPS/MS. Atenção às gestantes no contexto da pandemia do novo coronavírus SARS-COV2. Disponível em: https://portaldeboaspraticas.iff.fiocruz. br/biblioteca/gestantes-nota-tecnica-no-6-2020-cosmucgcivi-dapes-saps-ms/

11. WHO (World Health Organization). Clinical management of severe acute respiratory infection (SARI) when COVID19 disease is suspected; 2020. Disponível em: https://www.who.int/publications-detail/clinical-management-of-severe-acute-respiratory-infection-when-novelcoronavirus-(ncov)-infection-is-suspected

12. Duarte G, Quintana SM. Infecção pelo coronavírus SARSCoV-2 em obstetrícia. Enfrentando o desconhecido. Associação de Obstetrícia e Ginecologia de São Paulo. [acesso 21 mar 2020]. Disponível em: https:/www.sogesp.com.br/noticias/infeccao-pelo-coronavirus-sars-cov-2-em-obstetricia-enfrentando-o-desconhecido/
13. Poon LC, Yang H, Kapur A, Melamed N, Dao B, Divakar H, McIntyre HD,Kihara AB, Ayres-de-Campos D, Ferrazzi EM, Di Renzo GC, Hod M. Global interim guidance on coronavirus disease 2019 (COVID-19) during pregnancy and puerperium from FIGO and allied partners: Information for healthcare professionals. Int J Gynaecol Obstet. 2020; 149 (3): 273-86.

14. SBP (Sociedade Brasileira de Pediatria). Prevenção e Abordagem da Infecção por COVID-19 em mães e RecémNascidos, em Hospitais-Maternidades. Departamento Científico de Neonatologia - Sociedade Brasileira de Pediatria; 2020

15. ReHuNA (Rede pela Humanização do Parto e Nascimento) Recomendações para a assistência ao parto e nascimento em tempos de pandemia de covid-19: em defesa dos direitos das mulheres e dos bebês. 2020. Disponível em: https://docs.google.com/forms/d/e/1FAIpQLSeLHlkkF62R fO71L2162C7p5qDjArcs9agn-FJ85b8kKSSNGw/viewform

16. CDC (Centers for Disease Control and Prevention). Considerations for Inpatient Obstetric Healthcare Settings. 2020. Disponível em: https://www.cdc.gov/coronavirus/2019-ncov/hcp/inpatient-obstetric-healthcare-guidance.html

17. Brasil. Ministério da Saúde. Nota Técnica n ${ }^{\circ}$ 6/2020COCAM/CGCIVI/DAPES/SAPS/MS. Atenção à saúde do recém-nascido no contexto da infecção do novo coronavírus (sars-cov-2). Disponível em: http://www.crn2.org.br/ crn $2 /$ conteudo/nt\%206.pdf

18. SBP (Sociedade Brasileira de Pediatria). Medidas para o Pediatra relacionadas com a Pandemia do COVID-19. Departamento Científico de Infectologia - Sociedade Brasileira de Pediatria; 2020. Disponível em: https://www.sbp.com.br/fileadmin/user_upload/22426bInfectologia_-_NAlerta_-_Medidas_p_Pediatra relacionadas_COVID-19.pdf

19. CDC (Centers for Disease Control and Prevention). Interim considerations for infection prevention and control of coronavirus Disease 2019 (COVID-19) in inpatient obstetric healthcare settings; 2020. Disponível em: https://www.cdc.gov/coronavirus/2019-ncov/hcp/inpatientobstetric-healthcare-guidance.html

20. UNICEF (Fundo das Nações Unidas para a Infância). Coronavirus disease (COVID-19): What parents should know. How to protect yourself and your children; 2020. Disponível em: https://www.unicef.org/stories/novel-coronavirus- outbreak-what-parents-should- know

21. Brasil. Ministério da Saúde. Nota Técnica $n^{\circ} 7 / 2020$ DAPES/SAPS/MS. Disponível em: http://www.saude.sp. gov.br/resources/instituto-de-saude/homepage/pdfs/sei_ms0014033399-notatecnicaaleitamentoecovid.pdf

22. Marinelli KA. International Perspectives Concerning Donor Milk Banking During the SARS-CoV-2 (COVID-19) Pandemic. J Hum Lact. 2020; 36 (3): 492-7.

23. Brasil. Ministério da Saúde. Nota Técnica $n^{\circ} 5 / 2020$ COCAM/CGCIVI/DAPES/SAPS/MS. Condutas para doação de leite materno aos bancos de leite humano e postos de coleta de leite humano no contexto da infecção pelo coronavírus (SARS-CoV-2). Disponível em: 
https://www.conasems.org.br/wp-

content/uploads/2020/03/notatecnicaleitamento30mar202 0COVID-19.pdf

24. Rede Brasileira de Bancos de Leite Humano (rBLH) Ministério da Saúde. Fundação Oswaldo Cruz. Recomendação Técnica ${ }^{\circ}$ 01/20.170320. Disponível em: https://www.crn7.org/Arquivos/Uploads/2020/RBLH_Reso lucao012020-170320.pdf

25. Hong H, Wang Y, Chung H, Chen C. Clinical characteristics of novel coronavirus disease 2019 (COVID-19) in newborns, infants and children. Pediatr Neonatol. 2020; 61 (2): $131-2$

26. SBP (Sociedade Brasileira de Pediatria). Pais e filhos em confinamento durante a pandemia de COVID-19. Departamento Científico de Pediatria do Desenvolvimento e Comportamento; 2020. Disponível em: https://www.sbp.com.br/fileadmin/user_upload/22420cNAlerta_Pais_e_Filhos_em_confinamento_COVID-19.pdf
27. Sutton D, Fuchs K, D'Alton M, Goffman D. Universal Screening for SARS-CoV-2 in Women Admitted for Delivery. New Engl J Med. 2020; 382: 2163-4.

28. WHO (World Health Organization). WHO recommendations: intrapartum care for a positive childbirth experience. Geneva; 2018. Disponível em: https://apps.who.int/iris/bitstream/handle/10665/260178/97 89241550215-eng.pdf? sequence $=1$

29. Chen D, Yang H, Cao Y, Cheng W, Duan T, Fan C, et al. Expert consensus for managing pregnant women and neonates born to mothers with suspected or confirmed novel coronavirus (COVID-19). Infection. Int J Gynecol Obstet. 2020; 149: 1-7.

30. Manzo B, Costa ACL, Silva MD, Jardim DMB, Costa LO Separação inevitável do binômio mãe-bebê no pós-parto imediato na perspectiva materna. Rev Bras Saúde Mater Infant. 2018; 18 (3): 501-7.

Received on May 18, 2020

Approved on July 13, 2020 